\title{
Evidence for importance of gender and birth cohort for risk of IDDM in offspring of IDDM parents
}

\author{
J. Tuomilehto ${ }^{1}$, T. Podar ${ }^{2}$, E.Tuomilehto-Wolf ${ }^{1}$, E. Virtala ${ }^{1}$ \\ ${ }^{1}$ Department of Epidemiology and Health Promotion, National Public Health Institute, Helsinki, Finland \\ ${ }^{2}$ Republic Endocrinology Center, Tartu University, Tartu, Estonia
}

Summary The risk of developing diabetes is higher in offspring of fathers than of mothers with insulin-dependent diabetes mellitus (IDDM). The reasons for this sex differential are unclear, as early studies were often selected and relatively small. We conducted a prospective study on the risk of IDDM in a cohort of 9,453 offspring from 5,255 Finnish parents with diabetes diagnosed before age 30 years. Age of first admission to the hospital was considered to be the age of diagnosis of IDDM in the offspring; IDDM occurred in 248 offspring. The risk of IDDM tended to be lower in the offspring of the same gender as the diabetic parent (adjusted risk ratio (RR) $0.78 ; p=0.50$ ). When offspring were of same gender as the diabetic parent, male offspring had a higher risk of IDDM than female offspring (RR 2.28; $95 \%$ confidence interval 1.53-3.38), whereas if the gender of the diabetic parent and the offspring were different, the risk in male offspring was lower (RR 0.43 ; $95 \%$ confi- dence interval $0.31-0.62$ ). For the offspring of diabetic fathers, the cumulative risk by the age of 20 was higher $(7.6 \%)$ than for those with diabetic mothers $(3.5 \%)(p<0.0001)$. In a multivariate analysis statistically significant predictors of IDDM in the offspring were the sex of the parent, the year of birth and the birth order of the offspring. The risk of IDDM in the offspring increased by $9 \%$ per year of birth cohort. By age 20 , the cumulative risk of developing IDDM in the offspring of diabetic parents was $5.3 \%, 10$ times higher than in the background population. It is likely that genetic factors seem to have played a major role in the continuous increase of IDDM incidence in Finnish children. [Diabetologia (1995) 38: 975-982]

Key words Insulin-dependent diabetes mellitus, epidemiology, cumulative risk, sex differential, family history.
Although it is known that genetic factors play a major role in the aetiology of insulin-dependent diabetes mellitus (IDDM), not all genetically predisposed individuals develop the disease. Only about $25 \%$ of monozygotic twins are concordant for IDDM $[1,2]$ and only $15 \%$ of all HLA identical siblings of a dia-

Received: 6 September 1994 and in revised form: 28 February 1995

Corresponding author: Dr. J.Tuomilehto, National Public Health Institute, Department of Epidemiology and Health Promotion, Mannerheimintic 166, FIN-00300, Helsinki, Finland

Abbreviations: IDDM, Insulin-dependent diabetes mellitus; $\mathrm{CI}$, confidence interval; $\mathrm{RR}$, risk ratio. betic child will also become diabetic [3]. The mode of inheritance of IDDM has also remained elusive.

It is clear that the risk for the offspring of IDDM parents is higher than that for the background population [4-9] and that the risk for offspring of fathers with IDDM is higher than for those with mothers with IDDM, as Warram et al. [6] were the first to point out. This differential in maternal and paternal risk is poorly understood.

A number of studies have investigated the occurrence of diabetes in offspring of parents with IDDM. Most of them have been based on small samples and were hospital-based. There are two basic ways of designing parent-offspring studies; to ascertain the prevalence of diabetes in the parents of diabetic children, or prospectively to ascertain the incidence of diabe- 
Table 1. Descriptive data of the study population

\begin{tabular}{|c|c|c|c|c|c|}
\hline \multirow[t]{2}{*}{ Characteristics } & \multicolumn{2}{|c|}{ Female probands } & \multicolumn{2}{|c|}{ Male probands } & \multirow[t]{2}{*}{ All probands } \\
\hline & $n$ & $\operatorname{Age}^{a}$ & $n$ & Age $^{a}$ & \\
\hline Probands & 2960 & 36 & 2295 & 37 & 5255 \\
\hline Total offspring & 5251 & 11 & 4202 & 11 & 9453 \\
\hline Offspring with diabetes & 89 & 14 & 159 & 13 & 248 \\
\hline Percentage of offspring with diabetes & 1.7 & & 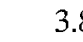 & & 2.6 \\
\hline Male offspring & 2650 & 11 & 2150 & 11 & 4800 \\
\hline Male offspring with diabetes & 50 & 14 & 72 & 14 & 122 \\
\hline Percentage of male offspring with diabetes & 1.9 & & 3. & & 2.5 \\
\hline Female offspring & 2601 & 11 & 2052 & 10 & 4653 \\
\hline Female offspring with diabetes & 39 & 13 & 87 & 12 & 126 \\
\hline Percentage of female offspring with diabetes & 1.5 & & 4. & & 2.7 \\
\hline \multicolumn{6}{|l|}{$\begin{array}{l}\text { Gender concordance between the diabetic } \\
\text { parent and the offspring controlled for age at } \\
\text { diagnosis }\end{array}$} \\
\hline $\mathrm{RR}$ & 0.7 & & 0. & & 0.79 \\
\hline $95 \% \mathrm{CI}$ & $0.52-1$ & & $0.56-$ & & $0.61-1.01$ \\
\hline
\end{tabular}

a Mean age (years) on 31 December 1989

tes in the offspring of the diabetic parent. The majority of studies have assessed the prevalence of diabetes in parents of newly diagnosed diabetic children. A much more informative though more difficult approach is to prospectively determine the cumulative risk of IDDM in the offspring of diabetic parents.

Finland has the highest incidence of IDDM in the world: 35.2 per 100,000 per year during 1987-1989 in the age group $0-14$ years $[10,11]$. Data from the nationwide "Childhood Diabetes in Finland" (DiMe) study initiated in 1986 show that the prevalence of IDDM in parents of children with IDDM diagnosed before 15 years of age is $4.1 \%$, in fathers $5.7 \%$ and in mothers $2.6 \%$ [10]. The aim of this paper is to find out whether a similar difference in the risk of IDDM can be detected between the offspring of diabetic fathers and mothers using a prospective study design. Recently, we collected data on the incidence of diabetes in the offspring of parents with diabetes in Finland. Here we report the cumulative risk and predictors of IDDM in a large cohort of offspring from Finnish parents with diabetes diagnosed before the age of 30 years.

\section{Materials and methods}

The Finnish Hospital Discharge Register, initiated in 1970 , contains information for each patient admitted to any hospital in Finland on the date of admission to the hospital, date of birth, personal identification number and up to four diagnoses as International Classification of Diseases (ICD) codes. To be eligible for the present study as a proband the subject had to be admitted to a hospital between 1970 and 1984, and diagnosed as having diabetes (ICD-250) before the age of 30 years. If the subject had been hospitalized more than once during that time period, the age at first admission was considered the age when the diagnosis of diabetes established.

These individuals were then linked through their personal identification number to the Finnish Population Register that contains information on every Finnish citizen that enabled us to link children to their parents. The diabetic status of the children was determined for the years 1970-1991 through the Hospital Discharge Register via the personal identification number. If a child had been hospitalized more than once during that period, the age at first admission was considered to be the age when the diagnosis of diabetes was made. Virtually all children with newly-diagnosed diabetes are hospitalized in Finland [10]. The year of birth of the diabetic parents (probands) varied from 1934 to 1970 .

We decided to restrict the analysis to offspring of probands who were discharged with a diagnosis of diabetes before the age of 30 , assuming that nearly all diabetes in the first 30 years of life is IDDM as confirmed by studies done in Sweden [12, 13]. The number of eligible female probands was 2,960 , and there were 2,295 male probands (Table 1 ). These 5,255 diabetic parents had 9,453 offspring, of whom 248 had been diagnosed as having diabetes. The mean age was similar between males and females, both in probands and in the offspring.

We compared the age at admission of the offspring given in the Hospital Discharge Register in a subset of 69 children to that registered in the Finnish Childhood Insulin-Dependent Diabetes Register. They had been discharged from hospital with the first established and validated diagnosis of diabetes during 1986-1989. The record linkage was again implemented through the personal identification numbers. In all 69 subjects the age at admission in the Hospital Discharge Register agreed with the age at diagnosis in the Finnish Childhood Insulin-Dependent Diabetes Register. Thus, the age at admission in the Hospital Discharge Register proved to be valid for the survival analysis.

\section{Statistical analysis}

Statistical analyses were done using SAS procedures LIFETEST and PHREG [14]. The risk of IDDM for the offspring was described as the proportion of offspring developing diabetes during the follow-up and as the cumulative incidence (cumulative risk). Cox proportional hazards model was used to investigate the significance of several risk predictors of diabetes. The difference in the duration of the diabetes-free period in the offspring with different predictor vectors was estimated by the log-rank test. Relative risks and $59 \%$ confidence inter- 
vals (95\% CI) between different strata were estimated from a conventional $2 \times 2$ table or using a Cox proportional hazards model when adjusting for covariates.

\section{Results}

A total of 5,261 probands with diabetes diagnosed before the age of 30 years had a total of 9,463 offspring (Table 1). Diabetes had developed in 248 offspring, 122 boys and 126 girls. The mean family size of male and female probands was similar; males had $1.83 \pm 0.89$ and females $1.78 \pm 0.88$ offspring.

Diabetes had developed in 88 of the 5,261 offspring of female probands. The occurrence of diabetes was much higher among the 4,202 offspring of male probands; 160 children had been diagnosed as diabetic.

Female offspring of female probands tended to have a lower risk of developing diabetes than male offspring controlling for the age-at-diagnosis of IDDM (risk ratio $(\mathrm{RR})=0.80$ ) (Table 1 ). The same was found for the male offspring of male probands, whose risk of developing diabetes was less than that for female offspring $(R R=0.80)$. Thus, in the combined analysis the risk for offspring of the same gender as the proband was reduced with an $\mathrm{RR}=0.79$ (95\% CI 0.61-1.01). There was a clear interaction between the gender of the offspring and the gender concordance between the diabetic parent and the offspring (Fig.1). If the offspring were the same gender as the diabetic parent, male offspring had a higher risk of IDDM than the female offspring (RR 2.28; $95 \%$ CI 1.53-3.38). On the contrary, if the gender of the offspring and the diabetic parent were different, the risk of IDDM in male offspring was lower than that in female offspring (RR $0.43 ; 95 \%$ CI 0.31 $0.62)$.

The cumulative risk in the offspring for developing diabetes by a certain age is given in Table 2 and Figure 1 . By the age of 20 , the cumulative risk of developing diabetes in the offspring of parents with diabetes diagnosed before the age of 30 years was $5.3 \%$ in Finland. In the offspring of male probands the risk was significantly higher $(7.6 \%)$ than in those of female probands $(3.5 \%)$. At any age, the risk in the off-

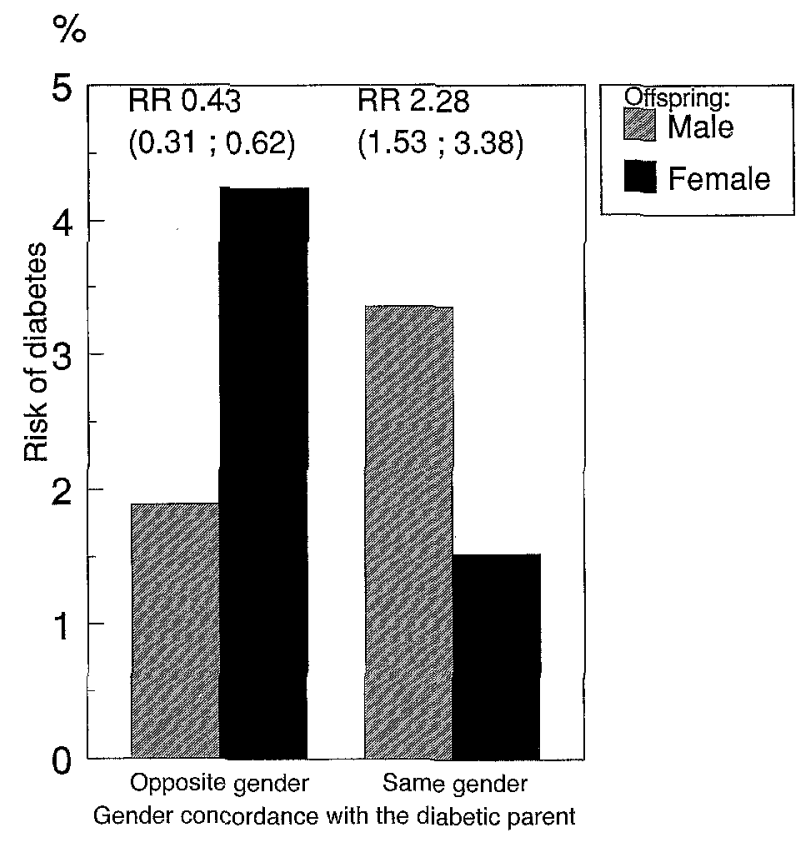

Fig. 1. Proportion of offspring with IDDM by gender of the offspring and by gender concordance with the diabetic parent

spring of diabetic fathers was approximately 2 times higher than that in the offspring of diabetic mothers (Table 2). The risk curves of developing diabetes (Fig.2) were significantly different for the offspring of male and female probands (Log-rank test: chisquare $=44.46, d f=1 ; p<0.0001$ ). To illustrate a possible birth cohort effect we also used an arbitrary cutoff point to classify offspring into two birth cohorts, born before and after 1975 . The offspring born after 1975 had a significantly higher cumulative risk of developing diabetes than those born prior to that year (Log-rank test 15.59, $d f=1, p<0.0004$ ) (Fig. 3). This effect was particularly strong in the offspring of diabetic fathers (RR 1.953; 95\% CI 1.35-2.83) and weaker in the offspring of diabetic mothers (RR 1.34; $95 \%$ CI $0.86-2.08$ ).

The distribution of diabetic cases within families of different sizes by birth order showed that the risk was about the same for each of the offspring (data not shown). In 3,259 families with at least two offspring the first-born child had a significantly lower risk of

Table 2. Cumulative risk of developing diabetes in the offspring of probands with diabetes diagnosed before the age of 30 years in Finland

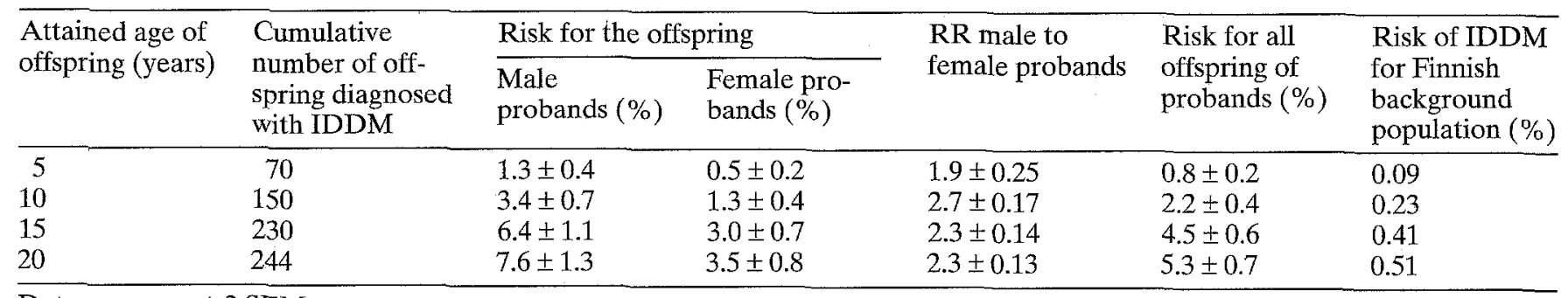

Data are mean \pm 2 SEM 
Table 3. The relative risk of diabetes in the offspring of diabetic parents by birth order of the offspring

\begin{tabular}{|c|c|c|c|c|}
\hline \multirow[t]{2}{*}{ Birth order of the offspring } & & \multicolumn{3}{|l|}{ Parent } \\
\hline & & Male & Female & All \\
\hline First-born vs others & $\begin{array}{l}\text { RR } \\
(95 \% \mathrm{CI})\end{array}$ & $\begin{array}{l}0.59 \\
(0.41 ; 0.85)\end{array}$ & $\begin{array}{l}0.83 \\
(0.51 ; 1.37)\end{array}$ & $\begin{array}{l}0.66 \\
(0.50 ; 0.89)\end{array}$ \\
\hline Last-born vs others & $\begin{array}{l}\text { RR } \\
(95 \% \mathrm{CI})\end{array}$ & $\begin{array}{l}1.44 \\
(1.00 ; 2.07)\end{array}$ & $\begin{array}{l}1.95 \\
(1.18 ; 3.12)\end{array}$ & $\begin{array}{l}1.61 \\
(1.20 ; 2.16)\end{array}$ \\
\hline
\end{tabular}

Table 4. The relative risk of diabetes in the offspring of diabetic parents by parental age at the birth of the offspring

\begin{tabular}{|c|c|c|c|}
\hline \multirow{2}{*}{$\begin{array}{l}\text { Parental age at } \\
\text { the birth of the } \\
\text { offspring }\end{array}$} & & \multicolumn{2}{|c|}{ Diabetic parent } \\
\hline & & Male & Female \\
\hline \multicolumn{4}{|l|}{ Univariate } \\
\hline linear & $\begin{array}{l}\text { RR } \\
(95 \% \mathrm{CI})\end{array}$ & $\begin{array}{l}1.03 \\
(1.00 ; 1.07)\end{array}$ & $\begin{array}{l}1.03 \\
(0.98 ; 1.09)\end{array}$ \\
\hline dichotomized $^{\mathrm{a}}$ & $\begin{array}{l}\text { RR } \\
(95 \% \mathrm{CI})\end{array}$ & $\begin{array}{l}1.19 \\
(0.86 ; 1.63)\end{array}$ & $\begin{array}{l}1.30 \\
(0.85 ; 2.00)\end{array}$ \\
\hline \multicolumn{4}{|l|}{ Adjusted } \\
\hline linear $^{b}$ & $\begin{array}{l}\text { RR } \\
(95 \% \mathrm{CI})\end{array}$ & $\begin{array}{l}0.99 \\
(0.95 ; 1.03)\end{array}$ & $\begin{array}{l}1.00 \\
(0.94 ; 1.06)\end{array}$ \\
\hline dichotomized $^{a}$ & $\begin{array}{l}\text { RR } \\
(95 \% \mathrm{CI})\end{array}$ & $\begin{array}{l}0.88 \\
(0.63 ; 1.23)\end{array}$ & $\begin{array}{l}1.09 \\
(0.69 ; 1.71)\end{array}$ \\
\hline
\end{tabular}

${ }^{a}$ Parental age at the birth of the offspring 24 years or under vs 25 years or more;

${ }^{b}$ Adjusted for the sex of the offspring and the year of birth of the offspring

developing IDDM (RR 0.66), or the risk in the lastborn child was increased (RR 1.61) (Table 3). Twothirds of these multiple-offspring families had only two children.

The effect of the age of the diabetic parent at the birth of the offspring was analysed in three different ways (Table 4). In the univariate analysis the risk of IDDM in the offspring increased slightly with the increasing age of parents at the birth of the child (RR for linear effect 1.03). This effect of parental age seemed to be confined to the subgroup of parents aged 25 years or older at the birth of the child, but the RRs of 1.19 and 1.30 for diabetic fathers and mothers, respectively, were not statistically significant. Moreover, adjustment for gender and year of birth of the offspring removed any possible effects of parental age at birth of the offspring on the risk of developing IDDM in the offspring.

The multivariate analysis of several variables that may influence the risk of diabetes in the offspring of diabetic parents was carried out in all families, and separately in families with two offspring or more and also stratified by the sex of the diabetic parent (Table 5). These analyses revealed that the sex of the diabetic parent, of the offspring and the diabetic parent having the same gender, year of birth of the offspring and birth order were statistically significant. The adjusted risk for the offspring of diabetic fathers was
2.41 times higher than that for those offspring of diabetic mothers. The risk of IDDM in the offspring increased each calendar year of birth by a factor of 1.09. In this multivariate analysis the offspring and the diabetic parent having the same gender became significant (RR $0.78 ; 95 \%$ CI $0.61-1.00 ; p=0.05$ ) after adjusting for effects of other factors. The age of the parent at birth of the offspring had no influence on the risk of IDDM for the offspring.

Birth order was a significant predictor of IDDM in the offspring. There was a tendency for the first-born child to have a lower risk of IDDM compared with the later-born children (RR 0.85), but this was not statistically significant. The last-born child had an increased risk of IDDM (RR 1.42; $p=0.008)$, an effect which was slightly stronger in families of diabetic mothers (RR $1.75 ; p=0.013)$ than in families of diabetic fathers (RR 1.27; NS).

\section{Discussion}

In contrast to other, smaller studies where male and female offspring were thought to be equally affected $[15,16]$, we found in our large population-based study that the gender of the offspring plays an important role in the transmission of the disease. Also, the fact that the incidence of IDDM under the age of 15 years is significantly higher in males than in females [10-12, 17] is consistent with our hypothesis that some genetic, hormonal or behavioural characteristics related to sex play a role in converting the underlying genetic susceptibility into overt IDDM. Also, in this study we found some evidence suggesting that the risk of IDDM was reduced for the offspring of diabetic parents who were of the same sex as the parent. Nevertheless, it is worth noticing that even though our prospective study was very large, we had only "a borderline power" to show a $20 \%$ effect of gender concordance between the diabetic parent and the offspring on the risk for IDDM in the offspring.

The effect of gender concordance between the diabetic parent and the offspring depended on the gender of the offspring. When the diabetic parent and the offspring shared the same gender, male offspring were at a higher risk of developing IDDM than female offspring, whereas if they were not the same gender, female offspring showed a higher risk. This 
Table 5. Predictors of risk of diabetes in offspring of parents with diabetes diagnosed before the age of 30 years

\begin{tabular}{|c|c|c|c|c|c|}
\hline Variable & $d f$ & Parameter estimate & Standard error & RR & $p$-value \\
\hline $\begin{array}{l}\text { Offspring and diabetic parent having same sex } \\
\text { Year of birth } \\
\text { Male sex of parent } \\
\text { Parent's age at the birth of the offspring }\end{array}$ & $\begin{array}{l}1 \\
1 \\
1 \\
1\end{array}$ & $\begin{array}{c}\text { All families } \\
-0.250 \\
0.089 \\
0.870 \\
0.009\end{array}$ & $\begin{array}{l}0.127 \\
0.016 \\
0.136 \\
0.017\end{array}$ & $\begin{array}{l}0.78 \\
1.09 \\
2.39 \\
0.99\end{array}$ & $\begin{aligned} & 0.050 \\
< & 0.0001 \\
< & 0.0001 \\
& 0.597\end{aligned}$ \\
\hline Parent's age at the birth of the offspring & & \multicolumn{3}{|c|}{ Families with at least two children } & \\
\hline Year of birth & 1 & 0.104 & 0.020 & 1.11 & $<0.0001$ \\
\hline $\begin{array}{l}\text { Parent's age at the birth of the offspring } \\
\text { Birth order }{ }^{\text {a: }}\end{array}$ & 1 & -0.257 & 0.022 & 0.98 & 0.254 \\
\hline - first-born vs others & 1 & -0.289 & 0.173 & 0.75 & 0.095 \\
\hline - last-born vs others & 1 & 0.235 & 0.166 & 1.27 & 0.155 \\
\hline \multicolumn{6}{|l|}{ Mother diabetic } \\
\hline - first-born vs others & 1. & 0.077 & 0.241 & 1.08 & 0.751 \\
\hline - last-born vs others & 1 & 0.557 & 0.274 & 1.75 & 0.013 \\
\hline \multicolumn{6}{|l|}{ All } \\
\hline $\begin{array}{l}\text { Sharing the same gender between the offspring } \\
\text { and the diabetic parent }\end{array}$ & 1 & -0.251 & 0.128 & 0.78 & 0.050 \\
\hline Year of birth & 1 & 0.088 & 0.016 & 1.09 & $<0.0001$ \\
\hline Parent's male sex & 1 & 0.881 & 0.136 & 2.41 & $<0.0001$ \\
\hline Parent's age at the birth of the offspring & 1 & -0.017 & 0.018 & 0.81 & 0.369 \\
\hline \multicolumn{6}{|l|}{ Birth order ${ }^{a}$ : } \\
\hline - first-born vs others & 1 & -0.161 & 0.140 & 0.85 & 0.249 \\
\hline - last-born vs others & 1 & 0.351 & 0.133 & 1.42 & 0.008 \\
\hline
\end{tabular}

${ }^{a}$ Two alternative parameters included in the model, each of them separately

effect was primarily due to the higher risk of IDDM in the offspring of diabetic fathers than diabetic mothers. A sex difference found for the transmission of any genetic trait can be explained either because the trait is sex-linked, sex-associated or because of a lower liability threshold or a greater penetrance in one sex. In sex-linked gene transmission a male will always inherit his $\mathrm{X}$ chromosome from his mother, since his father must contribute the $\mathrm{Y}$ chromosome. Consequently, a male can transmit the genetic information of his $\mathrm{X}$ chromosome to his grandchildren only via his daughters. A sex-associated effect in IDDM has been described in a study where fathers transmitted a certain HLA haplotype which confers genetic susceptibility to IDDM (A1, B8 haplotype) more often to male than to female offspring [18]. This haplotype showed preferential zygotic assortment over the alternative parental haplotype which could partially explain the increasing incidence of IDDM. In an analysis of DR locus alleles fathers were found to be more likely to transmit DR4 to their children than were mothers [19]. It has also been shown that Finnish fathers with IDDM are more likely to transmit high-risk susceptibility haplotypes to their offspring than mothers with IDDM [20].
Immunological mechanisms might be involved during pregnancy leading to tolerance and subsequently to the lower risk in offspring of mothers with IDDM compared with fathers with IDDM. The risk for children of IDDM mothers is still 5 times that for children of non-diabetic parents [6]. It has been clearly shown that perinatal mortality is not responsible for the lower risk in the offspring of IDDM mothers [16]. The role of maternal cytotoxic antibodies directed against the epitopes of the HLA molecules which develop during pregnancy and are elicited by fetal lymphocytes that cross the placenta has not been studied properly in diabetic pregnancies.

Other variables that influenced the risk of IDDM in the offspring, besides the sex shared between the diabetic parent and the offspring, were the year of birth of the offspring (birth cohort) and birth order. According to our estimates the risk of diabetes in the offspring of diabetic parents diagnosed under the age of 30 years increases about $9 \%$ per each yearly birth cohort. Therefore, the incidence of IDDM within these affected parent-child families increases faster than usual in Finland. A previous analysis of age, calendar period and birth cohort effects in 5,920 Finnish childhood IDDM patients showed an increasing linear trend of about $2.4 \%$ per year in the overall inci- 

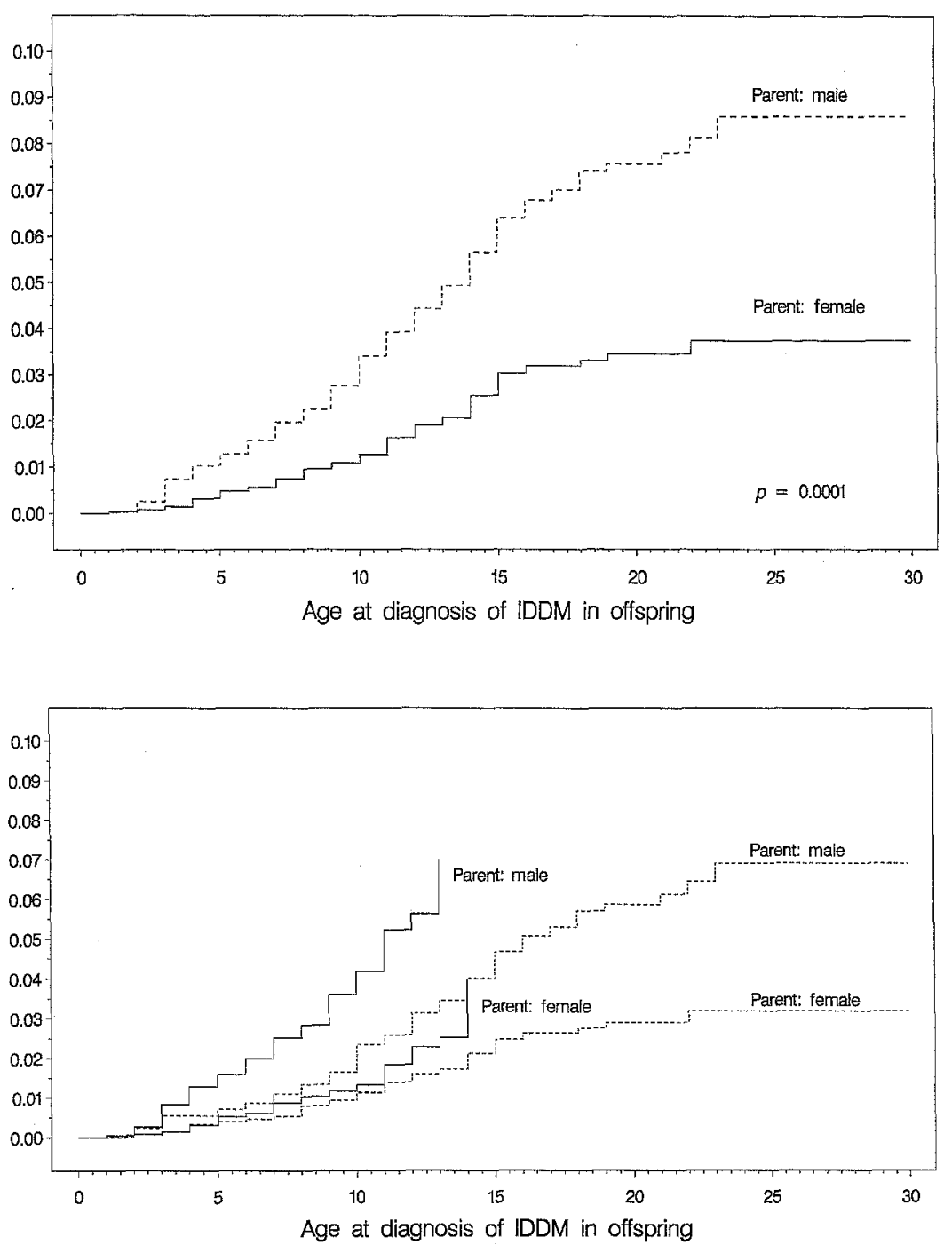

Fig. 2. Cumulative incidence of IDDM in offspring of mothers and fathers with diabetes diagnosed before the age of 30 years
Fig. 3. Cumulative incidence of IDDM in offspring of parents with diabetes diagnosed before the age of 30 years by birth cohort (offspring born 1975 or before (---) vs those born 1976 or later $(-))$ dence of IDDM [21]. Only a marginally significant birth cohort effect was seen in this previous study. It is possible that the birth cohort effect, which is relatively weak in the population at large, is due to a strong effect mainly coming from affected parent-offspring families.

Even though it has been claimed that the rapid increase in IDDM incidence, which was around $57 \%$ over the past 20 years in Finland, can only be explained by environmental factors [21, 22], differences in HLA frequencies between IDDM patients diagnosed in the early 1960s and mid-1980s have been reported in Finland [23]. The fact that the increase in IDDM incidence has now continued for 40 years and that the increase has been almost linear does not fit the hypothesis that some environmental exposure would be the main reason for this trend. Our present data also point to the role of genetic factors in the increase in IDDM incidence in Finland.

In this study we used an age at diagnosis of under 30 years as the sole criterion for the definition of IDDM in the probands. To check whether each of the probands was truly insulin-dependent would have been unreasonable considering the huge number. We admit that using the age criterion alone leads to a somewhat inaccurate definition of the diabetes type. However, recent data from Sweden, where the incidence of childhood diabetes is also high, show that the cumulative incidence of non-insulin-dependent diabetes is less than $5 \%$ of all cases of diabetes diagnosed by the age of $30[12,13]$.

The cumulative incidence of diabetes in the offspring of Finnish parents with IDDM is $5.3 \%$ by the age of 20 , whereas in the Finnish background population it was $0.5 \%$. The fact that the cumulative risk of IDDM in the offspring of diabetic parents was constantly about 10 times that in the background population at any attained age points towards a genetic effect. Even though it is difficult to compare the findings from different studies because of the different methods used for the cumulative risk estimates, the risk in Finland seems to be clearly higher than that reported from Denmark [7], Germany [4] and Pittsburgh, USA [8]. 
Using data from the Joslin Diabetes Clinic, Warram et al. [6] first demonstrated that the risk of IDDM is much higher for the offspring of fathers than of mothers with IDDM. These findings, which had been previously confirmed by other groups [4, 24], were again confirmed in our large populationbased study. The risk of developing diabetes in the offspring of fathers with IDDM is particularly high in the first decade of life. During the second decade the relative risk for the offspring of fathers with IDDM is reduced but remains over twice as high as for those of mothers with IDDM.

In the present study we were unable to confirm earlier findings that the risk of IDDM would be increased in offspring of diabetic mothers who gave birth before age 25 years compared with those who gave birth after age 25 years [25]. The age of diabetic parents at the birth of the offspring was not an independent predictor of IDDM in the offspring. Such an association seems to be explained by other factors. The effect of birth order raises interesting possibilities; since the first-born child of a diabetic parent has a lower risk than the later-born children, the increase in incidence of IDDM in Finland could be partly due to an increase in the size of families where a parent has IDDM. Unfortunately, we have no data on long-term trends in family size among childhoodonset IDDM patients. It is generally known that even in the 1960s women with IDDM were discouraged from having (many) children because of various risks to the mother and the offspring. So far, the reasons why first-born child may be "protected" are unclear. Since the parental age at the birth of the offspring and birth order are strongly correlated, it is possible that the higher risk of IDDM in later birth order siblings compared with the first-born is an alternative expression of maternal age [26].

Only a few prospective studies have been conducted so far on the risk of diabetes in the offspring of parents with IDDM [5-8, 15, 27]. Our prospective study is noteworthy because it has a very large number of probands $-5,255$, more than 15 times larger than in any former investigation. It forms an essential database for future studies on the transmission of genetic susceptibility and environmental events leading to IDDM. We have demonstrated that it is important to have a sufficiently large number of affected parent-offspring families in order to have enough power for the detection of epidemiological phenomena. More population-based data are needed to elaborate the importance of parental history and sex-related effects in the transmission of the disease from the diabetic parents to their offspring.

\section{References}

1. Barnett A, Eff C, Leslie RDG, Pyke DA (1981) Diabetes in identical twins. A study in 200 pairs. Diabetologia 20: $87-93$

2. Kaprio J, Tuomilehto J, Koskenvuo M et al. (1992) Concordance for type 1 (insulin-dependent) and type 2 (non-insulin-dependent) diabetes mellitus in a population-based co hort of twins in Finland. Diabetologia 35: 1060-1067

3. Tarn A, Dean B, Schwarz G et al. (1988) Predicting insulindependent diabetes. Lancet I: $845-850$

4. Tillil H, Köbberling J (1987) Age-corrected empirical genetic risk estimates for first degree relatives of IDDM patients. Diabetes 36: 93-99

5. Persson B, Gentz J, Möller E (1984) Follow-up of children of insulin-dependent (type 1) and gestational diabetic mothers. Acta Paediatr Scand 73: 778-784

6. Warram JH, Krolewski AS, Gottlieb MS, Kahn CR (1984) Differences in risk of insulin-dependent diabetes in offspring of diabetic mothers and diabetic fathers. $\mathrm{N}$ Engl $\mathrm{J}$ Med 311: 149-152

7. Degnbol B, Green A (1978) Diabetes mellitus among firstand second-degree relatives of early onset diabetics. Ann Hum Genet 42: 25-47

8. McCarthy B, Dorman J, Aston C, Gollin S (1991) The incidence of insulin-dependent diabetes mellitus (IDDM) among offspring of diabetic parents: a prospective study. 14th IDF Congress Satellite, Williamsburg, Va., USA (Abstract)

9. Podar T, Tuomilehto J, Tuomilehto-Wolf E, LaPorte RE, Dorman JS (1994) The risk of insulin-dependent diabetes in offspring of parents with insulin-dependent diabetes. In: Dorman JS (ed) Proceedings of the NATO Advanced Science Institute Series. New York: Plenum Press, pp 57-67

10. Tuomilehto J, Lounamaa $R$, Tuomilehto-Wolf $\mathrm{E}$ et al. (1992) Epidemiology of childhood diabetes mellitus in Finland - background of a nationwide study of type 1 (insulin-dependent) diabetes mellitus. Diabetologia 35: $70-76$

11. Karvonen M, Tuomilehto J, Libman I, LaPorte R for the WHO DIAMOND Project Study Group (1993) A review of the recent epidemiological data on the worldwide incidence of type 1 (insulin-dependent) diabetes mellitus. Diabetologia 36: $883-892$

12. Nyström L, Dahlquist G, Östman J et al. (1992) Risk of developing insulin-dependent diabetes mellitus (IDDM) before 35 years of age: indications of climatological determinants for age at onset. Int $\mathbf{J}$ Epidemiol 21: 352-358

13. Blohmé G, Nyström L, Arnqvist HJ et al. (1992) Male predominance of type 1 (insulin-dependent) diabetes mellitus in young adults: results from a 5-year prospective nationwide study of the 15-34-year age group in Sweden. Diabetologia 35: $56-62$

14. SAS Institute Inc. (1989) SAS/STAT user's Guide, Version 6. 4th edn., vol 1 and 2, SAS Institute Inc., Cary p. 943

15. Warram JH, Martin BC, Krolewski AS (1991) Risk of IDDM in children of diabetic mothers decreases with increasing maternal age at pregnancy. Diabetes 40: 16791684

16. Warram JH, Krolewski AS, Kahn R (1988) Determinants of IDDM and perinatal mortality in children of diabetic mothers. Diabetes 37: 1328-1334

17. Rewers M, LaPorte R, King HOM, Tuomilehto J, for the diabetes epidemiology research international study group (DERI) (1988) Insulin-dependent diabetes mellitus in childhood: international patterns and trends. World Health Stat Q 41: 179-189 
18. Cudworth AG, Gorsuch AN, Wolf E, Festenstein H (1979) A new look at HLA genetics with particular reference to type-1 diabetes. Lancet 2: 389-391

19. Vadheim CM, Rotter JI, Maclaren NK, Riley WJ, Anderson EA (1986) Preferential transmission of diabetic alleles within the HLA gene complex. N Engl J Med 80: 13141318

20. Tuomilehto-Wolf E, Tuomilehto J, Cepaitis Z, Lounamaa R and the DiMe Study Group (1989) New susceptibility haplotype for type 1 diabetes. Lancet II: 299-302

21. Tuomilehto J, Rewers M, Reunanen A et al. (1991) Increasing trend in type 1 (insulin-dependent) diabetes mellitus in childhood in Finland. Diabetologia 34: 282-287

22. Diabetes Epidemiology Research International (1987) Preventing insulin-dependent diabetes mellitus: the environmental challenge. BMJ 295: 479-481

23. Kontiainen S, Scheinin T, Schlenzka A, Mäenpää J, Groop L, Koskimies S (1988) Differences in HLA types in chil- dren with insulin-dependent diabetes diagnosed in 1960 's, 1970's and 1980's. Lancet II: 219

24. Gavard JA, Dorman JS, LaPorte RE (1989) An increased secondary attack rate of insulin-dependent diabetes mellitus for children of diabetic fathers compared with children of diabetic mothers. Am J Epidemiol 130: 822-823 (Abstract)

25. Warram J, Martin BC, Krolewski AJ (1991) Risk of IDDM in children of diabetic mothers decreases with increasing maternal age at pregnancy. Diabetes 40: 1679-1684

26. Flood T, Brink S, Gleason R (1982) Increased incidence of type 1 diabetes in children of older mothers. Diabetes Care 5: 571-573

27. Buschard K, Kühl C, Molsted-Pedersen L et al. (1989) Investigations in children who were in utero at onset of insulin-dependent diabetes in their mothers. Lancet I: 811-814 